\title{
Revisiting projected shifts in the climate envelopes of North American trees using updated general circulation models
}

\author{
DANIEL W. MCKENNEY*, JOHN H. PEDLAR*, RICHARD B. ROOD $†$ and DAVID PRICE \\ *Landscape Analysis and Applications Section, Canadian Forest Service, Great Lakes Forestry Centre, 1219 Queen Street E. Sault \\ Ste Marie, ON, Canada P6A 2E5, †Department of Atmospheric, Oceanic and Space Sciences, University of Michigan, 2455 \\ Hayward Street, Ann Arbor, Michigan 48109, USA, $\ddagger$ Natural Resources Canada, Canadian Forest Service, Northern Forestry \\ Centre, 5320 - 122nd Street, Edmonton, Alberta, Canada
}

\begin{abstract}
Global climate models are constantly being upgraded, but it is often not clear what these changes have on climate change impact projections. We used difference maps to directly compare downscaled projections of temperature and precipitation across North America for two versions (or generations) of three different Atmospheric-Ocean General Circulation Models (AOGCM)s. We found that AOGCM versions differed in their projections for the end of the current century by up to $4{ }^{\circ} \mathrm{C}$ for annual mean temperature and $60 \%$ for annual precipitation. To place these changes in an ecological context, we reanalyzed our work on shifts in tree climate envelopes (CEs) using the newer-generation AOGCM projections. Based on the updated AOGCMs, by the 2071-2100 period, tree CEs shifted up to 2.4 degrees further north or 2.6 degrees further south (depending on the AOGCM) and were about 10\% larger in size. Despite considerable differences between versions of a given AOGCM, projections made by the newer version of each AOGCM were in general agreement, suggesting convergence across the three models studied here. Assessing the AOGCM outputs in this way provides insight into the magnitude and importance of change associated with AOGCM upgrades as they continue to evolve through time.
\end{abstract}

Keywords: climate change, climate envelopes, general circulation models, North American trees, uncertainty

Received 7 December 2010; revised version received 3 February 2011 and accepted 4 February 2011

\section{Introduction}

If realized, the changes in climate projected for this century will bring about widespread changes in plant distributions, including range expansions, contractions, shifts, and extirpations (IPCC, 2007; Aitken et al., 2008). In fact, poleward and upslope shifts, at least partly attributed to climate warming, have already been documented for a number of plant species and regions (Bertin, 2008; Kelly \& Goulden, 2008; Woodall et al., 2009). In a previous study, we reported an average northward shift of $\sim 700 \mathrm{~km}$ and an area reduction of $\sim 12 \%$ in the climate envelopes (CEs) of 130 North American tree species based on atmosphere-ocean general circulation models (AOGCM) projections for the end of the current century (McKenney et al., 2007a). These findings are in general agreement with other comparable studies (Shafer et al., 2001; Hamann \& Wang, 2006). Although it is highly unlikely that tree species will actually track climate shifts, estimating the

Correspondence: Daniel W. McKenney, tel. +1 705541 5569, fax + 1705759 5700, e-mail: dmckenne@NRCan.gc.ca magnitude of these shifts helps elucidate the rate at which species will be compelled to migrate and informs the scale and scope of strategic forest management and conservation activities (Malcolm et al., 2002; Loarie et al., 2009).

Most projections of future climate are generated by AOGCMs - complex computer programs that encode basic laws of physics, fluid motion, and chemistry into a mathematical representation of the climate system (Heffernan, 2010). Simulations from 23 different AOGCMs, developed by research teams around the world, were reported by the Intergovernmental Panel on Climate Change (IPCC) for their fourth Assessment Report (AR4) (IPCC, 2007). These models are constantly being improved and updated as understanding of the earth's climate system advances and computational resources allow. Since the third Assessment Report (TAR) (IPCC, 2001), many of the models have undergone improvements in the areas of: core processes (e.g., advection), model resolution, aerosol dynamics, heat/moisture exchange at land and sea surfaces including the cryosphere, and parameterization of physical processes (IPCC, 
2007). Ongoing work also aims to represent biological processes, both on land and in the oceans, which are expected to respond to climatic changes with further effects on atmospheric GHG concentrations. While this constitutes an impressive list of improvements, it is not immediately clear how they affect the modeled changes in climate and hence how they will affect predicted future impacts on ecosystems and human infrastructure.

Uncertainty around future climate projections has been, and continues to be, a major deterrent to the initiation of climate change mitigation and adaptation activities (Lemos \& Rood, 2010; Rosentrater, 2010). Many studies have examined the various sources of uncertainty that impact climate projections, including natural climate fluctuations, differences between AOGCM models, and future emissions scenarios (Cox \& Stephenson, 2007; Meehl et al., 2007; Knutti et al., 2008; Hawkins \& Sutton, 2009). However, few studies have explored the variation associated with AOGCM upgrades (but see Reichler \& Kim, 2008) - even though such information can provide insight into the extent that climate models are capturing important climate processes. It might be expected that, over time, projections made by subsequent climate model versions would begin to converge as improvements increasingly fall under the rubric of 'fine-tuning'. However, uncertainty in future climate projections has reduced little since the first IPCC report in 1990 (Räisänen, 2007; Roe \& Baker, 2007) and Trenberth (2010) warns that AOGCM improvements made in preparation for the next IPCC report (i.e., AR5) may actually lead to more uncertainty in projected climate changes for the end of this century; clearly this topic deserves closer attention.

In this paper, we compare future climate projections for North America (Canada and continental United States including Alaska) based on estimates from the TAR- and AR4-generation of three different AOGCMs. To get an overall sense of the changes, we map the difference in future climate estimates for the two versions of each AOGCM. We then reanalyze our previous work on shifts in tree CEs (McKenney et al., 2007a) using the updated AOGCM outputs. This allows us to put the changes between AOGCM versions in the context of a particular conservation issue - namely the potential impacts of climate change on North American tree species. Assessing the AOGCM outputs in this way provides insight into the magnitude of change associated with AOGCM modifications and generally increasing complexity. Many jurisdictions are attempting to develop policy and management responses to pending climate changes - understanding the robustness of response models such as these is an important part of this process.

\section{Methods}

\section{AOGCM data}

Future climate projections from two versions of three different AOGCMs were used in this study. Basic information on each model, including major enhancements between versions, is provided in Table 1. We acknowledge that using three AOGCMs limits the scope of our findings, however, these models were selected because they are widely used in climate change impact studies and match those used in our previous work (McKenney et al., 2007a). All projections reported here are based on the A2 emissions scenario as described in Nakicenovic \& Swart (2000). This scenario assumes rapid population growth, a reduction in forested land, and increasing levels of pollution and GHG emissions as the century progresses.

The data were downloaded from either the Canadian Centre for Climate Modelling and Analysis (http://www.cccma. bc.ec.gc.ca/data/cgcm $3 / \mathrm{cgcm} 3 . s h t m l)$ for the Canadian AOGCM outputs, or from the 'WCRP CMIP3 multi-model dataset' archived at the Program for Climate Model Diagnosis and Intercomparison (https://esg.llnl.gov:8443/index.jsp) for all other models. The AOGCM outputs were downscaled as outlined in McKenney et al. (2006a). Briefly, this involved converting the raw AOGCM outputs, obtained in the form of monthly values for each year over the period 2001-2100, to anomalies centered on the 1961-1990 normal period. These anomalies were then averaged for three time periods (2011-2040, 20412070, and 2071-2100) and spatially continuous climate surfaces were generated for each period by interpolating the coarse-scale average change values using thin plate smoothing splines (Hutchinson, 2004). These change surfaces were then interrogated at the location of more than 7000 long-term climate stations in Canada and the United States and the predicted change projections for each month at that location added to the respective 1961-1990 station monthly normals. This provided a network of stations with projected climate values that include both well-established site-to-site variation in climate and the broad scale average changes predicted by the AOGCMs. Finally, these projected climate values at each station were again interpolated to produce a spatial grid for each climate variable and time period. Derived bioclimatic variables (e.g., mean annual temperature, annual precipitation, etc.) were generated from these monthly averages using ANUCLIM (Nix, 1986; Houlder et al., 2000). The same downscaling process was used for both versions of each AOGCM so any variation due to the methodology itself should be minimal. For the purposes of this exercise, the final resolution of the climate change grids was $\sim 10 \mathrm{~km}$

In order to compare temperature projections for the end of the century across AOGCM versions, annual mean temperature grids associated with the TAR- and AR4-versions of each of the AOGCMS were overlaid and a difference map was calculated. A similar procedure was followed for precipitation, but the difference was expressed as a percentage of current (1971-2000) precipitation levels. To put these differences in perspective, we also present maps showing the difference between current (1971-2000) and future (2071-2100) grids of temperature/precipitation. 
Table 1 Details on the AOGCM versions used in this study

\begin{tabular}{|c|c|c|c|c|}
\hline Developer & TAR-version & AR4-version & $\begin{array}{l}\text { Major improvements between } \\
\text { versions }\end{array}$ & References \\
\hline $\begin{array}{l}\text { Canadian Centre } \\
\text { for Climate } \\
\text { Modeling and } \\
\text { Analysis } \\
\text { (CCCMA), } \\
\text { Canada }\end{array}$ & CGCM2 & CGCM3.1 & $\begin{array}{l}\text { Horizonal resolution increased from } 608 \text { to } 680 \text { cells } \\
\text { More levels in the vertical } \\
\text { Improved land surface module, which includes } 3 \text { soil } \\
\text { layers, a snow layer, and a canopy layer } \\
\text { Improved convection algorithm } \\
\text { More detailed solar radiative heating module } \\
\text { Improved water vapour transport algorithm }\end{array}$ & $\begin{array}{l}\text { McFarlane et al. } \\
\text { (2005) }\end{array}$ \\
\hline $\begin{array}{l}\text { Commonwealth } \\
\text { Scientific and } \\
\text { Industrial } \\
\text { Research } \\
\text { Organisation } \\
\text { (CSIRO), } \\
\text { Australia }\end{array}$ & CSIRO-Mk2.0 & CSIRO-MK3.5 & $\begin{array}{l}\text { Horizonal resolution increased from } 528 \text { to } 2613 \text { cells } \\
\text { More levels in the vertical } \\
\text { Improved land surface module, which includes } 6 \text { soil } \\
\text { layers, } 3 \text { snow layers, and a land cover type } \\
\text { Improved convection algorithm } \\
\text { New prognostic cloud scheme; allows model to } \\
\text { generate its own physically based cloud properties, } \\
\text { based on cloud water and cloud ice } \\
\text { Improved water vapour transport using Semi- } \\
\text { Lagrangian algorithm }\end{array}$ & $\begin{array}{l}\text { Gordon et al. } \\
\quad(2002)\end{array}$ \\
\hline $\begin{array}{l}\text { National Center } \\
\text { for Atmospheric } \\
\text { Reaearch } \\
\text { (NCAR), USA }\end{array}$ & PCM & CCSM3.0 & $\begin{array}{l}\text { Horizonal resolution increased from } 1118 \text { to } 4368 \text { cells } \\
\text { More levels in the vertical } \\
\text { Greater detail in land-atmosphere flux components } \\
\text { New treatments of cloud processes } \\
\text { Improved aerosol radiative forcing } \\
\text { Improved ocean mixed layer processes } \\
\text { More realistic sea ice dynamics } \\
\text { Many others (see reference) }\end{array}$ & $\begin{array}{l}\text { Collins et al. } \\
\qquad(2006)\end{array}$ \\
\hline
\end{tabular}

\section{Tree CE reanalysis}

CE modeling is a widely used approach for summarizing species' climatic requirements and potential climate change impacts (Pearson \& Dawson, 2003). Here, we briefly outline our approach for assessing projected shifts in tree CEs; see McKenney et al. (2007a) for details. We used a well known, albeit simple, CE technique, as implemented in the ANUCLIM software package (Nix, 1986; Houlder et al., 2000). This method required geo-referenced occurrence data for each of the 130 trees species under study, along with climate estimates at each occurrence location. The tree data used here were gathered as part of a larger initiative, aimed at obtaining continent-wide distribution information for thousands of North American plants (McKenney et al., 2001, 2007b). Each tree species used in the study had at least 50 georeferenced occurrence locations $($ mean $=9912.5, \mathrm{SE}=1115.3$ ) that were well distributed across its published range (Little, 1971, 1977).

The ANUCLIM summaries provide an empirically based estimate of the full CE for each species (i.e., maximum and minimum values for each climate variable of interest) as well as a series of reduced (or 'core') envelopes which exclude potential outliers by returning climate values asso- ciated with predefined percentiles. Given that there may be differences in the size and shape of the predicted CE depending on the climate variables used, it is important (and challenging) to select appropriate variables for analysis (Beaumont et al., 2005). For the current work, we made use of variables that summarized two important climatic gradients for plants and animals - heat and moisture (Woodward, 1987). For heat, we selected annual mean temperature, minimum temperature of the coldest month, and maximum temperature of the warmest month. Moisture gradients were similarly summarized using annual precipitation, precipitation in the warmest quarter, and precipitation in the coldest quarter. Climate estimates for each of these variables were generated at each plant occurrence location from existing spline models covering the 1971-2000 normal period (see McKenney et al., 2006b for details). Full CEs were then generated for each species and located on maps of projected climate for each AOGCM version and time period. The size and centroid of each CE was determined, allowing changes in envelope area and latitude to be calculated for each time period and model. Maps of CE richness were generated by overlaying all of the $130 \mathrm{CEs}$ for a given time period and model and counting the number of envelopes that fall on each grid cell. 


\section{Results}

\section{Difference maps}

Figure 1 shows differences in the temperature field. In the left column (Fig. 1a, c and e) are differences of the 30 -year average at the end of the 21st century from the 1971 to 2000 baseline. All newer AOGCMs projected warming of $>5^{\circ} \mathrm{C}$ in the far north, $<3^{\circ} \mathrm{C}$ in the southeastern and far western regions, and $3-5^{\circ} \mathrm{C}$ for much of the midcontinent region. The central part of the continent warms more relative to coastal regions.

The right-hand panels (Fig. 1b, $d$ and f) show differences between older and newer versions of, nominally, the same institutional model for 2071-2100 period. Differences in mean annual temperature between TAR- and AR4-versions were highly dependent on the AOGCM. The CGCM showed relatively minor changes between model versions (generally within $\pm 2{ }^{\circ} \mathrm{C}$ ), with CGCM3.1 projecting cooler temperatures than CGCM2 for the central US and warmer temperatures in the western and northeastern regions of the continent (Fig. 1b). The CSIRO-mk3.5 version projected cooler temperatures across much of the continent compared with its predecessor, with the largest differences $\left(<-4{ }^{\circ} \mathrm{C}\right)$ occurring in the northeast region (Fig. 1d). CCSM3.0 projected considerably warmer temperatures for all of North America as compared with the earlier PCM version, with differences of $>3^{\circ} \mathrm{C}$ for much of the central portion of the continent (Fig. 1f).

Figure 2 shows differences in annual precipitation. All of the newer AOGCMs projected much of the continent to have precipitation levels that vary between $-20 \%$ and $40 \%$ of current (1971-2000) levels, with consistent increases across Alaska and northern Canada (Fig. 2a, c and e). South of these approximately coherent signals, the spatial patterns in projected precipitation differ from model to model, with: CGCM3.1 projecting declines in the far southwest (Fig. 2a); CSIRO-mk3.5 projecting declines across much of the southern US (Fig. 2c); and CCSM3.0 projecting declines for much of western North America (Fig. 2e).

Differences in annual precipitation between model versions were again highly dependent on the AOGCM (Fig. 2b, d and f). CGCM3.1 projected precipitation levels in the far southwest region that were 20-60\% lower than CGCM2 projections; along with pockets in the southeast, northeast, and northcentral regions where projections were 20-60\% higher than CGCM2 (Fig. 2b). CSIRO-mk3.5 projected precipitation levels that were $20-60 \%$ higher than CSIRO-mk2 for much of central and southwestern US and relatively small changes for the rest of the continent (Fig. 2d). Similarly, CCSM3.0 projected increases in precipitation of $20-60 \%$ over the PCM version for much of the southwestern and eastern US and the far north (Fig. 2f).

\section{Tree CEs}

With respect to latitudinal shifts in the 130 tree CEs, the difference between AOGCM versions was highly dependent on the AOGCM (Table 2). There was relatively little difference between the latitude shifts predicted by the TAR and AR4-version of the CGCM; tree CEs were projected to shift slightly further north under the newer AOGCM version in each time period. Conversely, a smaller northward shift was projected for each time period under the AR4-version of the CSIRO CGM. This was particularly noticeable in the 2071-2100 time period, when the average projected shift under the AR4version was 2.6 degrees south of the TAR-version. The NCAR model showed an opposite pattern, with the newer version predicting larger northward shifts than the earlier version in each time period - the difference was 2.4 degrees of latitude in the final time period. These differences between the two versions of each AOGCM led to considerable convergence across the newer versions. Under the TAR version, the CSIRO AOGCM projected the largest average northward shift in CEs (8.7 degrees) followed by the CGCM (6.5 degrees) and NCAR (4.5 degrees); under the AR4-version, all the AOGCMs project a northward shift between 6 and 7 degrees.

Apart from the CGCM in the first time period, the AR4-version of each AOGCM projected increases in CE size (Table 3). On average, projected CE size was about $10 \%$ larger under the AR4 version of the AOGCMs. The CGCM showed the greatest variation, with CE size projected to decline in the first time period by $7.3 \%$ under the AR4-version as compared with a $2.9 \%$ decline under the TAR version. By the final time period, the AR4-version of the CGCM was projecting an average increase in CE size of $13.9 \%$ vs. a $6.4 \%$ decline under the TAR version. Both of the other AOGCMs projected larger CE sizes under the AR4 in each time period. There is again some evidence of convergence across the AR4 AOGCM estimates with projected increases in CE size ranging from $13.9 \%$ for CGCM3.1 to $27.5 \%$ for CCSM3.0; the TAR versions varied from $-6.4 \%$ for CGCM2 to $12.6 \%$ for PCM.

An overall impression of how these intergenerational differences in AOGCM projections impact shifts in these 130 tree species CEs can be obtained by observing difference maps of $\mathrm{CE}$ richness - i.e., the change, over time, in the number of species' CEs projected to occupy a map grid cell (Fig. 3). The figure illustrates the relatively small changes across the CGCM models (Fig. 3a and b), the smaller northward shifts associated 

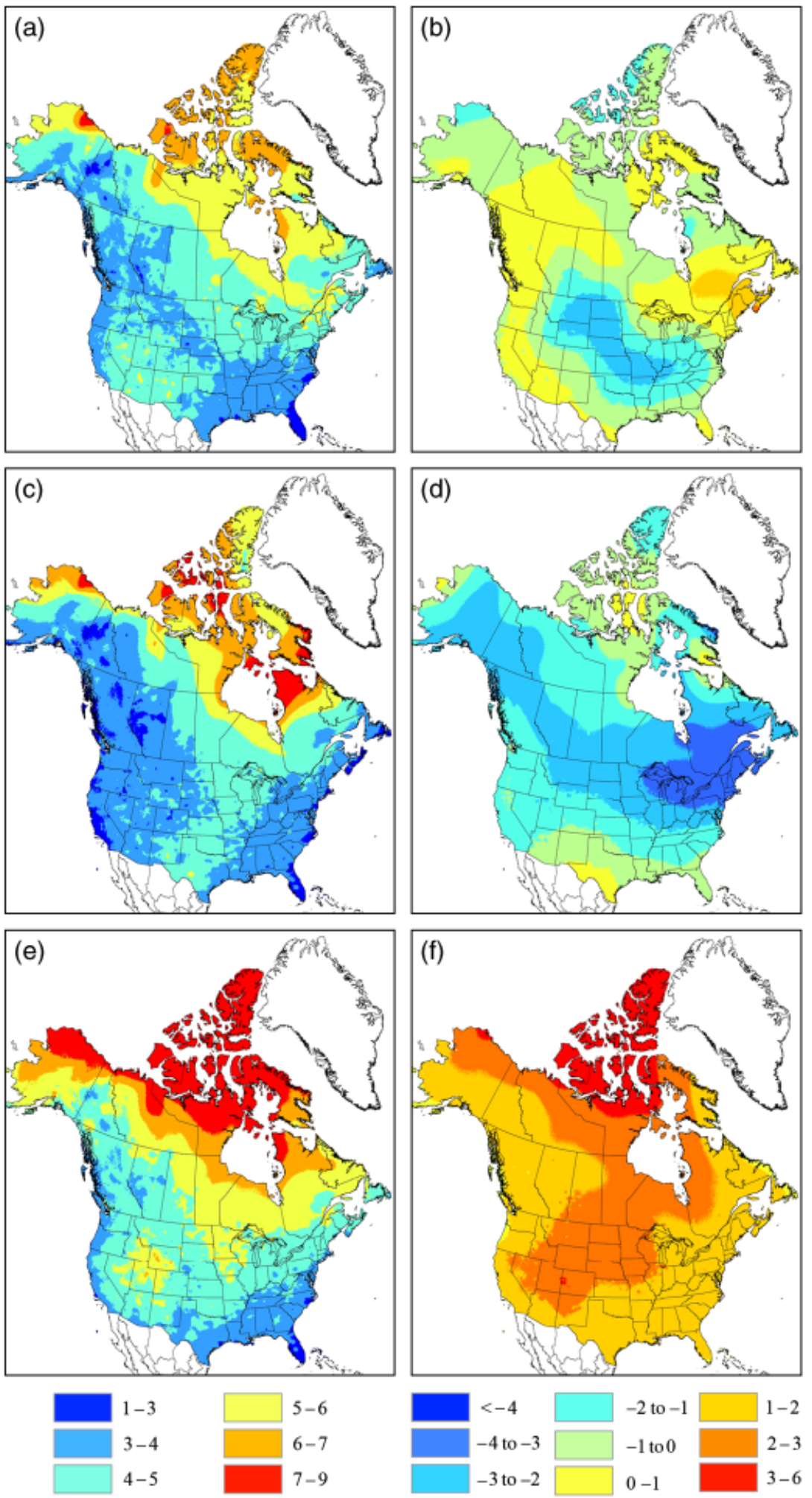

Fig. 1 Differences between current (1971-2000) and future (2071-2100) mean annual temperature $\left({ }^{\circ} \mathrm{C}\right)$ are shown in the left panels for: (a) CGCM3.1 minus current, (c) CSIRO-mk3.5 minus current, and (e) CCSM3.0 minus current. Differences in projected (2071-2100) mean annual temperature between AOGCM versions are shown in the right panels for: (b) CGCM3.1 minus CGCM2, (d) CSIRO-mk3.5 minus CSIRO-mk2, and (f) CCSM3.0 minus PCM. Full AOGCM names are provided in Table 1. 

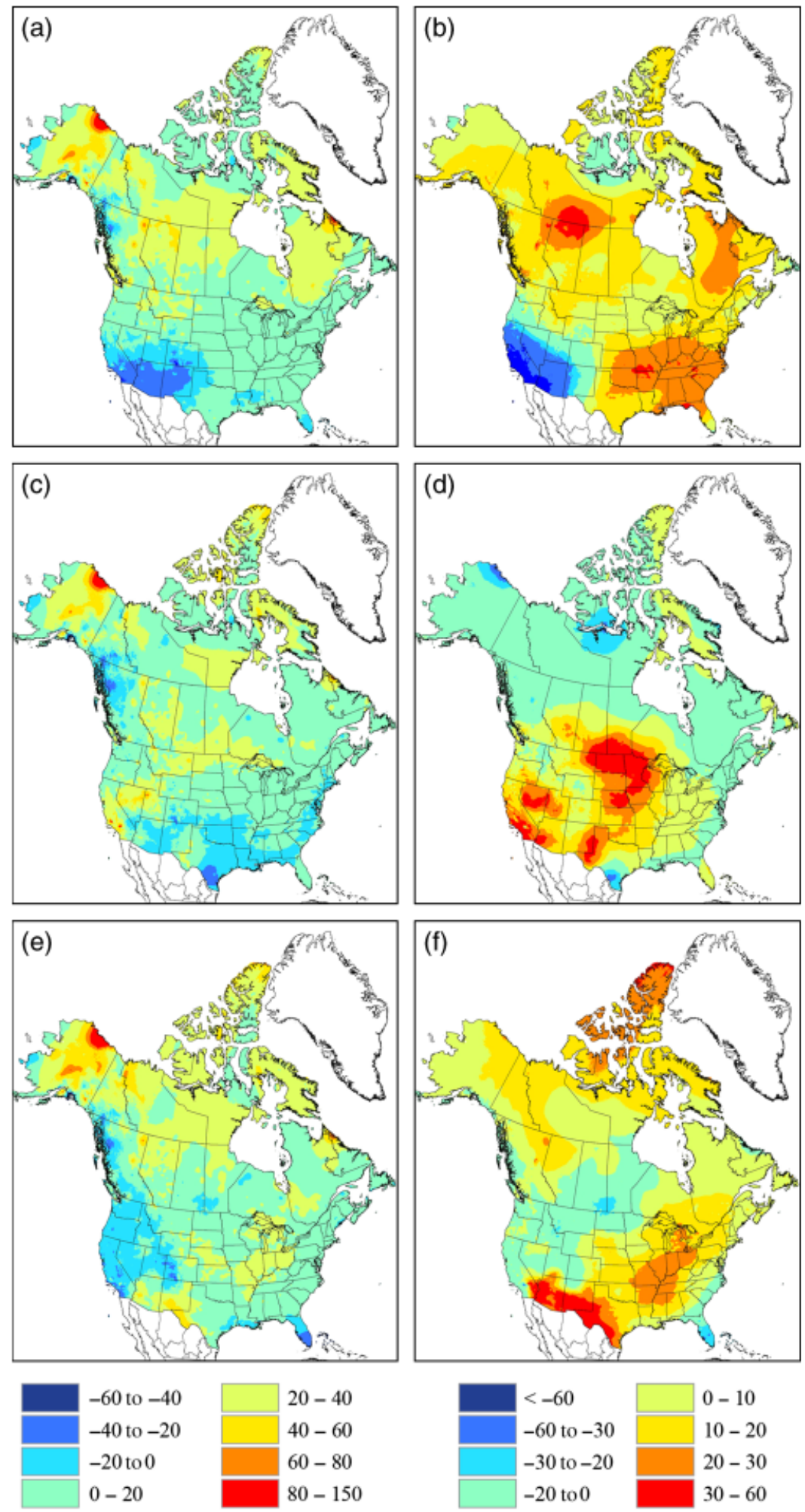

Fig. 2 Differences between current (1971-2000) and future (2071-2100) annual precipitation (expressed as a percentage of current values) are shown in the left panels for: (a) CGCM3.1 minus current, (c) CSIRO-mk3.5 minus current, and (e) CCSM3.0 minus current. Differences in projected annual precipitation between AOGCM versions (expressed as a percentage of current values) are shown in the right panels for: (b) CGCM3.1 minus CGCM2, (d) CSIRO-mk3.5 minus CSIRO-mk2, and (f) CCSM3.0 minus PCM. Full AOGCM names are provided in Table 1. 
Table 2 The average ( \pm SD) northward shift (in degrees of latitude) in the climate envelopes of 130 North American tree species under earlier (TAR) and updated (AR4) versions of three different AOGCMs

\begin{tabular}{|c|c|c|c|c|c|c|}
\hline \multirow[b]{2}{*}{ Period } & \multicolumn{2}{|l|}{ CGCM } & \multicolumn{2}{|l|}{ CSIRO } & \multicolumn{2}{|l|}{ NCAR } \\
\hline & TAR-version & AR4-version & TAR-version & AR4-version & TAR-version & AR4-version \\
\hline 2011-2040 & $1.8 \pm 0.8$ & $2.4 \pm 0.7$ & $2.3 \pm 0.7$ & $1.8 \pm 0.6$ & $1.1 \pm 0.5$ & $2.2 \pm 0.7$ \\
\hline 2041-2070 & $4.1 \pm 1.2$ & $4.4 \pm 1.1$ & $4.9 \pm 1.1$ & $3.8 \pm 0.9$ & $2.6 \pm 0.7$ & $4.5 \pm 1.2$ \\
\hline 2071-2100 & $6.5 \pm 1.7$ & $6.6 \pm 1.5$ & $8.7 \pm 1.6$ & $6.1 \pm 1.4$ & $4.5 \pm 1.2$ & $6.9 \pm 1.6$ \\
\hline
\end{tabular}

Table 3 The average ( \pm SD) change in size (\%) of the climate envelopes of 130 North American tree species under earlier (TAR) and updated (AR4) versions of three different AOGCMs

\begin{tabular}{|c|c|c|c|c|c|c|}
\hline \multirow[b]{2}{*}{ Period } & \multicolumn{2}{|l|}{ CGCM } & \multicolumn{2}{|l|}{ CSIRO } & \multicolumn{2}{|l|}{ NCAR } \\
\hline & TAR & AR4 & TAR & AR4 & TAR & AR4 \\
\hline 2011-2040 & $-2.9 \pm 13.9$ & $-7.3 \pm 11.5$ & $0.2 \pm 9.6$ & $4.5 \pm 10.3$ & $-6.2 \pm 9.9$ & $10.4 \pm 13.8$ \\
\hline 2041-2070 & $-5.7 \pm 28.0$ & $3.4 \pm 21.3$ & $6.1 \pm 19.0$ & $6.5 \pm 17.2$ & $2.6 \pm 13.3$ & $15.2 \pm 19.4$ \\
\hline $2071-2100$ & $-6.4 \pm 39.3$ & $13.9 \pm 31.1$ & $3.5 \pm 27.2$ & $16.8 \pm 30.9$ & $12.6 \pm 25.0$ & $27.5 \pm 26.9$ \\
\hline
\end{tabular}

with the updated CSIRO model (Fig. 3c and d), and the larger northward shifts associated with the updated NCAR model (Fig. 3e and f); convergence across the three modelling groups is also apparent (Fig. $3 b, d$ and $\mathrm{f}$ ). All of the AOGCMs project substantial reductions in CE richness across the eastern half of the United States, gains in CE richness for much of Canada, and relatively little change across much of the mountainous regions of the United States. These maps only indicate where suitable climatic conditions will exist for the 130 tree species under study; the extent to which trees will actually shift with climate is of course highly uncertain as discussed below.

\section{Discussion}

Our results show large differences between the TARand AR4-versions for two of the three AOGCMs under study. The largest difference was observed between the older and newer version of the NCAR model, and approached the magnitude of the average change in climate projected for this century. This is perhaps not surprising given the substantial changes that went into the new model. In fact, CCSM3.0 actually represents several versions worth of enhancements/improvements over PCM (Kiehl \& Gent, 2004; Collins et al., 2006). The higher temperature values associated with CCSM3.0 are primarily due to an updated land component which includes improved biogeophysical parameterizations that address significant biases in previous model versions (Bonan et al., 2002). Similarly, the large differences between CSIRO-mk3.5 and CSIRO-mk2 in projected mean annual temperature are presumably related to the extensive modifications to the land surface module employed in the newer version (Gordon et al., 2002). Interestingly, there was relatively little change between versions of the CGCM despite the enhancements to CGCM3.1.

Differences between AOGCMs and emissions scenarios have been identified as major sources of uncertainty in future climate projections (Hawkins \& Sutton, 2009). These sources have been shown to contribute about equally to the overall range in 'likely' temperature estimates of $1.1{ }^{\circ} \mathrm{C}-6.4^{\circ} \mathrm{C}$ for the end of the current century (IPCC, 2007; Knutti et al., 2008). Thus, the variation reported here across AOGCM versions of approximately $2{ }^{\circ} \mathrm{C}-3{ }^{\circ} \mathrm{C}$ is comparable to that reported for other major sources of uncertainty. We note that these findings are limited to the three AOGCMs studied here. In fact, ensemble estimates of average global temperature for the end of this century have changed relatively little between the TAR and the AR4 (IPCC, 2007; Knutti et al., 2008), suggesting that the substantial intergenerational differences demonstrated here vary according to the AOGCM and the spatial scale under study. Nonetheless, climate change impact and adaptation studies often employ projections from a limited number of AOGCMs to a particular region of interest; our results indicate that these projections could change substantially across AOGCM versions.

It is the implication of these differences that is important to those interested in climate change impacts and vulnerability. Not surprisingly, differences in future climate projections between AOGCM versions trans- 

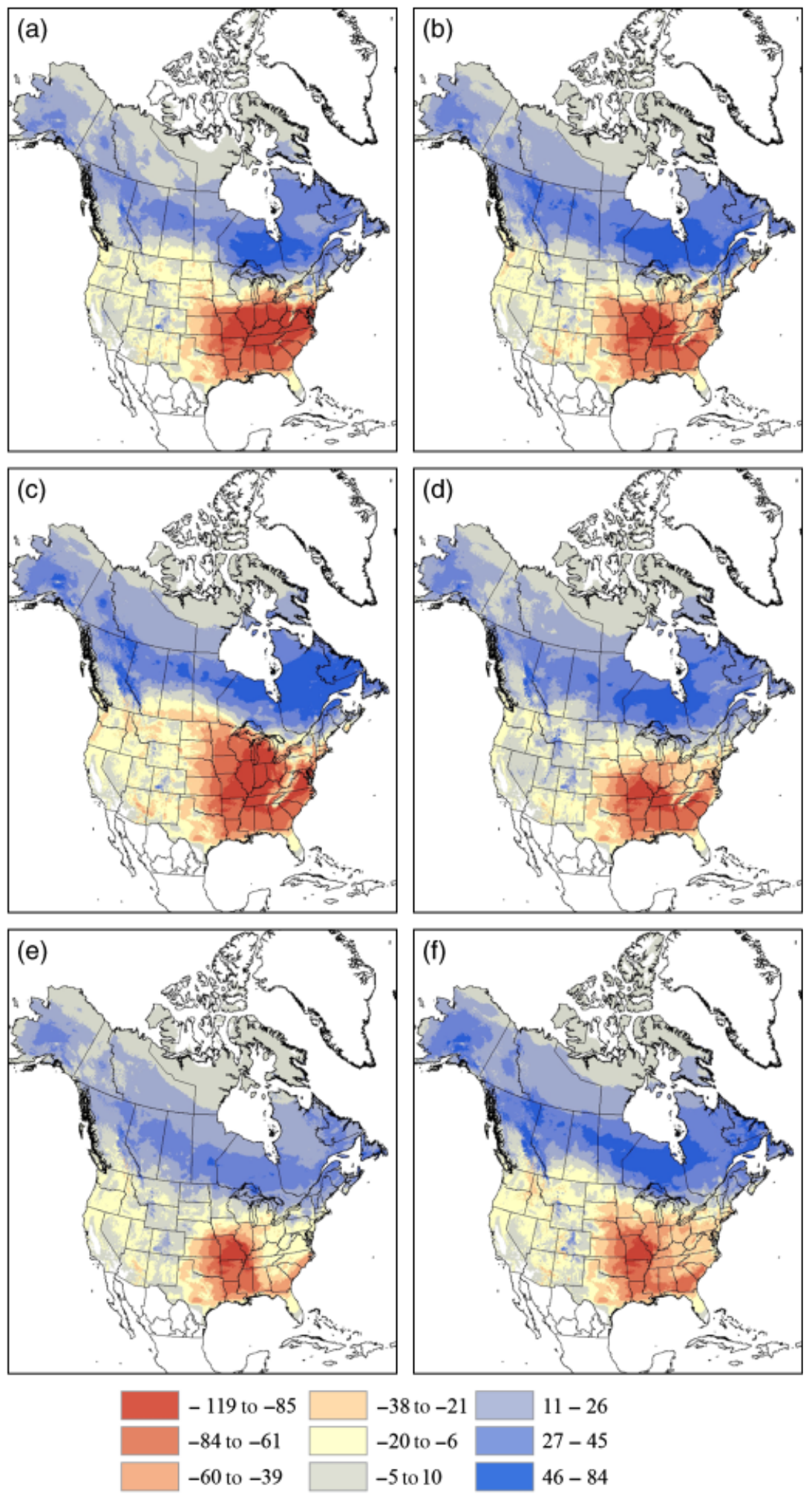

Fig. 3 Differences between current (1971-2000) and future (2071-2100) tree climate envelope richness (i.e., number of tree species) for: (a) CGCM2, (b) CGCM3.1, (c) CSIRO-mk2, (d) CSIRO-mk3.5, (e) PCM, and (f) CCSM3.0. Full AOGCM names are provided in Table 1. 
lated into differences in projected tree CE shifts. With respect to shifts in latitude, the results were closely related to the temperature differences reported across versions of each AOGCM; CSIRO-mk3.5 projected shifts that were 2.6 degrees of latitude south of the TAR version, while CCSM3.0 shifted the envelopes 2.4 degrees of latitude north of the TAR version. These are substantial differences in the context of tree species migration, which is estimated to occur at a rate of $<10 \mathrm{~km}$ per century (McLachlan et al., 2005).

Since climate change is projected to happen at a much faster rate than plant migration, it has been proposed that some species may need to be 'assisted' in order to track climate shifts (McLachlan et al., 2007). This assisted migration or colonization (Hunter, 2007) would likely make use of maps that show where species' CEs are projected to occur in the future (in conjunction with knowledge of local site conditions). Our findings indicate that there could be a $200-300 \mathrm{~km}$ difference in where CEs are located on maps of future climate depending on which AOGCM version is used - even when the GHG forcing assumptions are identical. Given that variation between AOGCM versions is just one of many uncertainties involved in spatial projections of future climate, assisted migration programs should likely target the central, or core, area of future CEs when identifying potential translocation sites. Results concerning changes in CE size were less drastic, with an overall projected size increase of about $10 \%$ using the updated AOGCM models. Again, in the context of assisted migration, targeting the central region of the future $\mathrm{CE}$ would reduce the chance of moving plants into outlying locations with unsuitable future climate conditions.

As a consequence of the relatively dramatic changes in climate resulting from the SRES A2 forcing scenario, large shifts were projected for the CEs studied here, indicating the potential for significant changes in tree species composition across North America. We note however, that the extent to which individual tree species will actually shift through natural processes interacting with climate change is highly uncertain, involving complex interacting factors such as: competitive, predatory, and mutualistic relationships among species (Davis et al., 1998; Hampe, 2004), edaphic and land-use considerations (Iverson \& Prasad, 1998), dispersal ability (Lawton, 2000; Hampe, 2004), genetic controls (e.g., Aitken et al., 2008; Kuparinen et al., 2009), $\mathrm{CO}_{2}$ fertilization effects (Wullschleger et al., 2002), and disturbance patterns (Schneider et al., 2009). Several studies have incorporated a number of these factors into projected range shifts in an effort to make the results more realistic (e.g., Iverson et al., 2005; Schneider et al., 2009; Midgley et al., 2010); though this also requires incorporating more assumptions into the modeling process (see also Araujo \& Rahbek, 2006). Here, we have purposely used a very simple and transparent approach, which nonetheless indicates the magnitude of the problem that climate change poses for tree species and helps to inform the scale at which assisted migration efforts would have to be undertaken to promote successful plant conservation. Furthermore, the simple approach employed here is well suited for studying the differences between AOGCM versions, as any changes in projected range shifts are directly related to changes in the AOGCM outputs. Several studies have recommended using multiple species distribution models in an ensemble framework to assess potential climate impacts on species distributions (Araujo \& New, 2007; Buisson et al., 2010). As a final check on the appropriateness of our approach, we reran the analysis using MAXENT (Phillips et al., 2006), a sophisticated machine-learning method, with no change to our qualitative findings.

Our findings illustrate the issue of uncertainty in the AOGCM projections - a key factor in the extent to which climate projections are generally accepted and incorporated into policy and decision making (Lemos \& Rood, 2010). If AOGCM projections for a given region are changing by several degrees for temperature and more than $20 \%$ for precipitation across AOGCM versions, how much faith can be put in the estimates provided by a given version? Clearly if this magnitude of change, across wide geographic areas, were to accompany each AOGCM upgrade, it would seriously erode confidence in the projections.

There are several signs, however, that suggest this is not the case. First, although we found substantial differences between versions of a given AOGCM, there appears to be convergence across the various modelling groups with respect to projected patterns of change for both temperature and precipitation. Although the maps in the left-hand column of Figures 1 and 2 are not perfect matches, there are far more similarities than differences, suggesting that the latest version of the AOGCMs agree on many of the general patterns of climate change (see also IPCC, 2007). For example, all of the models represent the polar amplification of global warming in the northern hemisphere, whose fingerprint has already been seen in the observational record of temperatures of the past several decades (Holland \& Bitz, 2003). While convergence does not necessarily imply improved accuracy (the newer model versions could simply be consistently inaccurate), its absence would suggest that the various climate modelling groups continue to differ widely in their interpretation of key processes and parameters. The convergence observed here is likely a result of world-wide commu- 
nication and comparison of model structures, coupled with ongoing research into land, ocean, and atmospheric processes; all of which are improving model representation of the climate system as a whole.

Furthermore, climate models are still in a fast development phase where known biases are being addressed and unrepresented processes are being incorporated. Given the complex nature of the phenomena that are being modelled, it is not surprising that relatively large differences are apparent between versions. Presumably, as the craft of climate modelling continues to be honed, the differences between model versions will become smaller. In support of this, Reichler and Kim (2008) tested the ability of three generations of climate models to model present (i.e., 1979-1999) climate and reported improved performance with each successive generation. They concluded that, while current models are not perfect, they are much more realistic than their predecessors.

Despite the apparent improvement in climate model outputs over time, levels of uncertainty may still be too high for some regional applications. However, careful interpretation of model outputs may help to reveal patterns of uncertainty, thus allowing work to move ahead in areas where projected climate change is relatively certain. For example, in this study a major component of the signal is related to the large warming that occurs at continental high latitudes in the northern hemisphere. This is a signal that is not only predicted by all modeling systems, but whose underlying physics is basically understood and well resolved by models. In addition, there is already substantial evidence of observed high latitude continental warming over the past century. This increases the confidence that there will be warming across much of Canada that will likely overwhelm natural rates of tree migration (Holland \& Bitz, 2003).

The models also provide a relatively similar signal for precipitation changes in the southeastern US (i.e., $\pm 20 \%$ ). However, the physics that are responsible for summertime precipitation in this region are small scale compared with model resolution. In addition to scale, there are numerous documented shortcomings in the representation of precipitation processes (Lee et al., 2007; Lim \& Roderick, 2007). Therefore, we can use the consistency of the models, and our understanding of the physics, to say that drastic changes in precipitation are not likely in this region. However, management action based on the fine-scale pattern of changes projected by the three simulations is not, as yet, warranted.

This combination of observations, knowledge of underlying mechanisms, and guidance from climate projections suggests an iterative strategy of planning and adaptation. Regional signals that are projected consis- tently across AOGCMs, well understood, and already beginning to emerge, are likely actionable. The fact that projections are relatively insensitive to emissions scenarios on time scales of approximately 40 years (IPCC, 2007) removes some ambiguity in decision making. The fact that many of the processes yet to be incorporated into AOGCM models (i.e., carbon cycling, ice sheets) are important on time scales of many decades to centuries, again, allows considered use of information with large impacts on decadal scales, like the forest impacts discussed here. Finally, the systematic improvement of AOGCM model simulations suggests that more refined and robust information will emerge on the time scale of years.

\section{Acknowledgements}

We gratefully acknowledge the assistance of Kathy Campbell, Kevin Lawrence, Marty Siltanen, and Pia Papapdopal in the preparation of this manuscript. Richard B. Rood's participation is sponsored by NOAA Climate Program Office grant NA10OAR4310213, and this represents the Great Lakes Regional Integrated Sciences and Assessments Center (/GLISA/) Contribution \# 1. Support was also provided from Natural Resources Canada, Canadian Forest Service Climate Change Adaptation Project.

\section{References}

Aitken SN, Yeaman S, Holliday JA, Wang TL, Curtis-McLane S (2008) Adaptation, migration or extirpation: climate change outcomes for tree populations. Evolutionary Applications, 1, 95-111.

Araujo MB, New M (2007) Ensemble forecasting of species distributions. Trends in Ecology and Evolution, 22, 42-47.

Araujo MB, Rahbek C (2006) How does climate change affect biodiversity? Science, 313, 1396-1397.

Beaumont LJ, Hughes L, Poulsen M (2005) Predicting species distributions: use of climatic parameters in BIOCLIM and its impact on predictions of species' current and future distributions. Ecological Modelling, 186, 250-269.

Bertin RI (2008) Plant Phenology and Distribution in Relation to Recent Climate Change. Journal of the Torrey Botanical Society, 135, 126-146.

Bonan GB, Oleson KW, Vertenstein M, Levis S (2002) The land surface climatology of the Community Land Model coupled to the NCAR Community Climate Model. Journal of Climate, 15, 3123-3149.

Buisson L, Thuiller W, Casajus N, Lek S, Grenouillet G (2010) Uncertainty in ensemble forecasting of species distribution. Global Change Biology, 16, 1145-1157.

Collins WD, Bitz CM, Blackmon ML et al. (2006) The Community Climate System Model Version 3 (CCSM3). Journal of Climate, 19, 2122-2143.

Cox P, Stephenson D (2007) A changing climate for prediction. Science, 317, 207-208.

Davis AJ, Jenkinson LS, Lawton JH, Shorrocks B, Wood S (1998) Making mistakes when predicting shifts in species range in response to global warming. Nature, 391, 783-786.

Gordon HB, Rotstayn LD, McGregor JL et al. (2002) The CSIRO Mk3 climate system model. Technical Paper No. 60, CSIRO Atmospheric Research, Aspendale, Victoria, Australia.

Hamann A, Wang T (2006) Potential effects of climate change on ecosystem and tree species distribution in British Columbia. Ecology, 87, 2773-2786.

Hampe A (2004) Bioclimate envelope models: What they detect and what they hide. Global Ecology and Biogeography, 13, 469-471.

Hawkins EE, Sutton RR (2009) The potential to narrow uncertainty in regional climate predictions. Bulletin of the American Meteorological Society, 90, 1095-1107.

Heffernan O (2010) The climate machine. Nature, 463, 1014-1016.

Holland MM, Bitz CM (2003) Polar amplification of climate change in coupled models. Climate Dynamics, 21, 221-232. 
Houlder DJ, Hutchinson MF, Nix HA, McMahon JP (2000) ANUCLIM User Guide, Version 5.1. Canberra, Australia: Centre for Resource and Environmental Studies, Australian National University.

Hunter ML Jr (2007) Climate change and moving species: furthering the debate on assisted colonization. Conservation Biology, 21, 1356-1358.

Hutchinson MF (2004) ANUSPLIN Version 4.3. Centre for Resource and Environmental Studies, Australian National University. Available at: http://cres.anu.edu.au/out puts/anusplin.php (accessed 8 October 2007)

Iverson L, Prasad A, Schwartz M (2005) Predicting potential changes in suitable habitat and distribution by 2100 for tree species of the eastern United States. Journal Agricultural Meteorology, 61, 29-37.

Iverson LR, Prasad AM (1998) Predicting abundance of 80 tree species following climate change in the eastern United States. Ecological Monographs, 68, 465-485.

IPCC (2001) Climate change 2001: The scientific basis. In: Contribution of Working Group I to the Third Assessment Report of the Intergovernmental Panel on Climate Change (eds Houghton JT et al.), Cambridge University Press, Cambridge, UK, New York, NY USA.

IPCC (2007) Climate change 2007: the physical science basis. In: Contribution of Working Group I to the Fourth Assessment Report of the Intergovernmental Panel on Climate Change (eds Solomon S, Qin D, Manning M, Chen Z, Marquis M, Averyt KB, Tignor M, Miller HL), Cambridge University Press, Cambridge, UK, New York, NY, USA

Kelly AE, Goulden ML (2008) Rapid shifts in plant distribution with recent climate change. Proceedings of the National Academy of Sciences of the United States of America, 105, 11823-11826.

Kiehl JT, Gent PR (2004) The community climate system model, version 2. Journal of Climate, 17, 3666-3682.

Knutti R, Allen MR, Friedlingstein P et al. (2008) A review of uncertainties in global temperature projections over the twenty-first century. Journal of Climate, 21, 2651-2663.

Kuparinen A, Savolainen O, Schurr FM (2009) Increased mortality can promote evolutionary adaptation of forest trees to climate change. Forest Ecology Manag ement, 259, 1003-1008.

Lawton JL (2000) Concluding remarks: a review of some open questions. In: Ecological Consequences of Heterogeneity (eds Hutchings MJ, John E, Stewart AJA), pp. 401-424 Cambridge University Press, Cambridge, UK.

Lee MI, Schubert SD, Suarez MJ et al. (2007) An analysis of the warm season diurnal cycle over the continental United States and northern Mexico in general circulation models. Journal of Hydrometeorology, 8, 344-366.

Lemos MC, Rood RB (2010) Climate projections and their impact on policy and practice. Wires Climate Change, 1, 670-682.

Lim WH, Roderick ML (2007) An Atlas of the Global Water Cycle Based on the IPCC AR4 Climate Models. ANU E Press, Canberra, Australia.

Little EL Jr (1971) Atlas of United States Trees, vol. 1: Conifers and Important Hardwoods. Washington, DC: US Department of Agriculture. Miscellaneous publication no. 1146.

Little EL Jr (1977) Atlas of United States Trees, vol. 4: Minor Eastern Hardwoods. Washington, DC: US Department of Agriculture. Miscellaneous publication no.1342.

Loarie SR, Duffy PB, Hamilton H, Asner G, Field CB, Ackerly DD (2009) The velocity of climate change. Nature, 462, 1052-1055.

Malcolm JR, Markham A, Neilson RP, Garaci M (2002) Estimated migration rates under scenarios of global climate change. Journal of Biogeography, 29, 835-849.

McFarlane NA, Scinoca JF, Lazare M, Harvey R, Verseghy D, Li J (2005) The CCCMa third generation atmospheric general circulation model (AGCM3). CCCMa Internal Report, 25pp.

McLachlan J, Clark J, Manos P (2005) Molecular indicators of tree migration capacity under rapid climate change. Ecology, 86, 2088-2098.

McLachlan JS, Hellmann JJ, Schwartz MW (2007) A framework for debate of assisted migration in an era of climate change. Conservation Biology, 21, 297-302.
McKenney DW, Hutchinson MF, Kesteven JL, Venier LA (2001) Canada's plant hardiness zones revisited using modern climate interpolation techniques. Canadian Journal of Plant Science, 81, 129-143.

McKenney DW, Papadopol P, Campbell K, Lawrence K, Hutchinson MF (2006b) Spatial Models of Canadian and North American-Wide 1971/2000 Minimum and Maximum Temperature, Total Precipitation and Derived Bioclimatic Variables. Sault Ste. Marie (Ontario): Canadian Forest Service Front Line Technical Note no. 106.

McKenney DW, Pedlar JH, Lawrence K, Campbell K, Hutchinson MF (2007a) Potential impacts of climate change on the distribution of North American trees. BioScience, 57, 939-948.

McKenney DW, Pedlar J, Lawrence K, Campbell K, Hutchinson M (2007b) Beyond traditional hardiness zones: using climate envelopes to map plant range limits. BioScience, 57, 929-937.

McKenney DW, Price D, Papadapol P, Siltanen M, Lawrence K (2006a) High-resolution climate change scenarios for North America. Sault Ste. Marie (Ontario): Canadian Forest Service Front Line Technical Note no. 107.

Meehl G, Covey C, Delworth Tet al. (2007) The WCRP CMIP3 multimodel dataset: a new era in climate change research. Bulletin of the American Meteorological Society, $\mathbf{8 8}$ 1383-1394.

Midgley GF, Davies ID, Albert CH et al. (2010) BioMove - an integrated platform simulating the dynamic response of species to environmental change. Ecography, 33 $1-5$.

Nakicenovic N, Swart R) eds (2000) Special Report on Emissions Scenarios. University Press, Cambridge, UK

Nix H (1986) A biogeographic analysis of Australian elapid snakes. In: Australia Flora and Fauna Series No. 7 - Atlas of Elapid Snakes of Australia (ed Longmore R), pp. 4-15. Bureau of Flora and Fauna, Canberra, Australia.

Pearson RG, Dawson TP (2003) Predicting the impacts of climate change on the distribution of species: are bioclimate envelope models useful? Global Ecology and Biogeography, 12, 361-371.

Phillips SJ, Anderson RP, Schapire RE (2006) Maximum entropy modeling of species geographic distributions. Ecological Modelling, 190, 231-259.

Räisänen J (2007) How reliable are climate models? Tellus, 59A, 2-29.

Roe GH, Baker MB (2007) Why is climate sensitivity so unpredictable? Science, 318, 629-632.

Reichler T, Kim JS (2008) How well do coupled models simulate today's climate? Bulletin of the American Meteorological Society, 89, 303-311.

Rosentrater L (2010) Representing and using scenarios for responding to climate change. Interdisciplinary Reviews Climate Change, 1, 253-259.

Shafer SL, Bartlein PJ, Thompson RS (2001) Potential changes in the distributions of western North America tree and shrub taxa under future climate scenarios. Ecosystems, 4, 200-215.

Schneider R, Wang X, Boutin S, Hamann A, Farr D (2009) Potential effects of climate change on ecosystem distribution in Alberta. Canadian Journal Forest Research, 39 1001-1010.

Trenberth K (2010) More knowledge, less certainty. Commentary Nature Reports Climate Change, Published online: 21 January 2010, doi: 10.1038/climate.2010.06

Woodall CW, Oswalt CM, Westfall JA, Perry CH, Nelson MD, Finley AO (2009) An indicator of tree migration in forests of the eastern United States. Forest Ecology and Management, 257, 1434-1444.

Woodward FI (1987) Climate and Plant Distribution. Cambridge University Press, Cambridge, UK.

Wullschleger SD, Tschaplinski TJ, Norby RJ (2002) Plant water relations at elevated $\mathrm{CO}_{2}$ - implications for water-limited environments. Plant, Cell and Environment, 25, 319-331. 